\title{
The Perfect Storm: Coronavirus (Covid-19) Pandemic Meets Overfat Pandemic
}

\author{
Philip B. Maffetone ${ }^{1 *}$ and Paul B. Laursen ${ }^{2}$ \\ ${ }^{1}$ Independent Researcher, Ormond Beach, FL, United States, ${ }^{2}$ Auckland University of Technology, Auckland, New Zealand
}

Keywords: Covid-19, infectious disease, chronic disease, obesity, pandemic, immunity, lifestyle

\section{INTRODUCTION}

In December, 2019, China's Wuhan city became the center of an outbreak of pneumonia of unknown cause, and by January, Chinese scientists reported to have isolated a novel coronavirus, severe acute respiratory syndrome coronavirus 2 (SARS-CoV-2; previously known as 2019-nCoV), from the infected patients $(1,2)$. The virus was later designated coronavirus disease 2019 (COVID19) in February by the World Health Organization (3).

Other respiratory infectious pathogens, including strains of influenza virus type A and adenovirus (ADV), such as H1N1, H7N9, ADV 7, and ADV 55, often lead to worldwide outbreaks that seriously endanger human health. For example, by the end of 2009, the local H1N1 flu epidemic peaked in most countries with $\sim 70,000$ laboratory-confirmed hospitalized patients and over 2,500 fatal cases observed across 19 countries (4).

The earliest scientific data on Covid-19 from China shows those most vulnerable to infection have pre-existing illness that includes diabetes, hypertension, cardiovascular disease, and chronic inflammation $(1,5,6)$. Many of these conditions are caused by excess body fat; a condition termed overfat $(7,8)$. The overfat condition itself is a significant yet little discussed risk factor in infectious viral diseases $(9,10)$, with overfat negatively affecting immune function and host defense mechanisms (11). It has been shown that both viral and bacterial pathogenesis is adversely altered in overfat hosts (11-14). While the viral infections all have different responses in human hosts, albeit similar, hospitals, and other critical care centers are applying their knowledge and skills concerning influenza to those with Covid-19 until more data and research is available specific to the Covid-19 virus (15).

Some viruses have high intrinsic levels of pathogenicity, mediating significant tissue damage in larger numbers of infected individuals, including smallpox and Ebola, with increased risk of death (16). While the Covid-19 produces symptoms common in other viral infections (such as fever, dry cough, dyspnea), it targets the lower airways to increase respiratory tissue damage, producing significantly high levels of plasma pro-inflammatory cytokines (17). In addition, some unique clinical features include upper respiratory tract symptoms like rhinorrhoea, sneezing, and sore throat, intestinal symptoms like diarrhea, and tissue infiltration of the upper lobe of the lung (17). Covid-19 also targets the central nervous system (18). It may be too early to know whether Covid19 is capable of immune evasion (the blunting of an effective immune response) associated with increased tissue damage, especially in those with impaired immunity (16).

Currently, there are no specific or effective antiviral drugs, nor vaccines against COVID-19 infection, for potential therapy of humans (17). This makes prevention through healthier lifestyle an important underutilized and significant preventive measure. While extensive measures to reduce person-to-person transmission of COVID-19, like other infectious agents, are required to control the current outbreak, important preventive measures associated with lifestyle can help reduce the risks of future outbreaks. 
The early death cases of COVID-19 were shown to occur primarily in elderly people who often have poor immune function that permits faster progression of viral infection (19). While most viral pandemics have similarities despite different pathogens, most hospitalizations occur among persons $<2$ years of age or 65 years of age or older, and among patients with certain medical conditions. One exception was during the 2009 pandemic influenza A (H1N1), which spread globally, with smaller numbers of severe illnesses reported among persons 65 years of age or older ( $\sim 5 \%)(20)$.

While children have yet to develop full natural immunity, the elderly may have impaired immune responses. However, age may not be a single susceptibility, as many older individuals are physiologically more functional, possessing healthier lifestyles that include healthy eating and physical activities, in addition to potential genetic benefits (21).

The Covid-19 pandemic is spreading rapidly throughout the world, with few effective tools to help treat those who are sick. Current treatment strategies are limited to quarantine, isolation, and implementation of infection-control measures to prevent spread (22).

As of March 31, 2020, 750,890 cases and 36,405 deaths due to coronavirus disease 2019 (COVID-19), caused by the novel severe acute respiratory syndrome coronavirus 2 (SARS-CoV-2), had been reported worldwide (23).

As with reports out of China and Italy, data from the U.S. demonstrates those at higher risk for Covid-19 had chronic conditions, with $78 \%$ of COVID-19 patients requiring admission to the intensive care unit (ICU) and $94 \%$ of hospitalized patients who died had an underlying condition (24). Underlying conditions included diabetes, cardiovascular disease, chronic lung disease (including asthma, chronic obstructive pulmonary disease, and emphysema), hypertension, and cancer $(1,5,6)$. Most of these underlying conditions are caused by or are associated with excess body fat $(8,25)$.

While those $\geq 65$ years of age were more at risk, those admitted to the ICU in the age bracket of 19-64 years also had significantly more chronic illness than those hospitalized without ICU admission $(23,24)$. These conditions are primarily caused by excess body fat and its associated chronic inflammation $(8,25)$. These and other analyses may be limited by relatively small numbers, missing data due to the burden placed on reporting health departments, and the rapidly rising number of cases $(23,24)$.

Initial indications in the U.S. showed that fatality was highest in persons aged $\geq 65$ years, $1-3 \%$ among persons aged 55-64 years, $<1 \%$ among persons aged $20-54$ years, while no fatalities occurred among persons aged $\leq 19$ years (26). Worldwide, mortality is expected to vary with the underlying chronic illness, with the risks associated with COVID-19 heavily influenced by the presence of these comorbidities $(1,5,6,27)$.

\section{THE HIDDEN OVERFAT PANDEMIC}

The overfat pandemic and its associated chronic inflammation and insulin resistance, and downstream chronic disease represents one of the greatest threats to global human health (28). Excess body fat is a primary driver of chronic inflammation, insulin resistance, and many downstream chronic illnesses, including cardiovascular disease, diabetes, hypertension, liver and kidney disease, cancer, and others (7, 8, 29), including increased risk of respiratory infections and inflammatory lung diseases (30).

During and after the 2009 influenza A/H1N1 pandemic, body mass index (BMI) was recognized as an independent risk factor for influenza, in particular, the severity of the illness, hospitalization, increased risk of spreading the disease, and death $(9,10)$. Data from past pandemics and seasonal influenza demonstrate that obesity is an independent risk factor for severe outcomes $(10,31)$.

Unfortunately, most metrics used in studies of influenza and other viral infections use obesity as a metric, and not adiposity, which may be a better metric to define this relationship between excess body fat and influenza (31). Even more important is the fact that 40 percent or more of normal-weight non-obese adults may have excess body fat that impairs their health-the condition called overfat (Figure 1) (7).

\section{OVERFAT AND IMPAIRED IMMUNITY}

Adipose tissue is a multifunctional endocrine organ involved in many physiological and metabolic processes, and is also populated by a number of immune cells including $\mathrm{T}$ lymphocytes and macrophages $(32,33)$. Excess body fat, however, can impair immunity, with obese individuals having a higher incidence of immune and autoimmune diseases (28). Excess body fat can contribute to cardiovascular and metabolic health impairment including various risk factors such as abnormal blood glucose, high-density lipoprotein cholesterol (HDL), triglycerides, and blood pressure, which progress to a variety of diseases including type 2 diabetes, non-alcoholic fatty liver, cancers, Alzheimer's, and cardiovascular diseases (34-36).

While humans are constantly infected with multiple endogenous and exogenous viral agents, with an estimated generation of up to $10^{12}$ new virus particles per day, a healthy immune system protects us in most situations from illness (37). However, the metabolic dysregulation of an overfat body can compromise the immune system to increase the risk of infections, and chronic respiratory diseases $(38,39)$. Overfat has also been shown to aggravate the effect of seasonal influenza on respiratory mortality independent of the effect of comorbidities and meteorological factors (31). As illustrated in Figure 2, excess body fat has been proposed as a driver of poor $\mathrm{T}$ cell and macrophage function, reduced antiviral responses and efficacy, increased viral shedding and subsequent transmission $(12,32,33,40,41)$. While vaccines have been the hallmark of primary preventive measures against many infections, it appears vaccines also work less effectively in an overfat body (42).

Overfat hosts also may have a breakdown of the respiratory epithelium leading to fluid influx in the airway space (43), with obese mice more likely than lean mice to have increased lung 


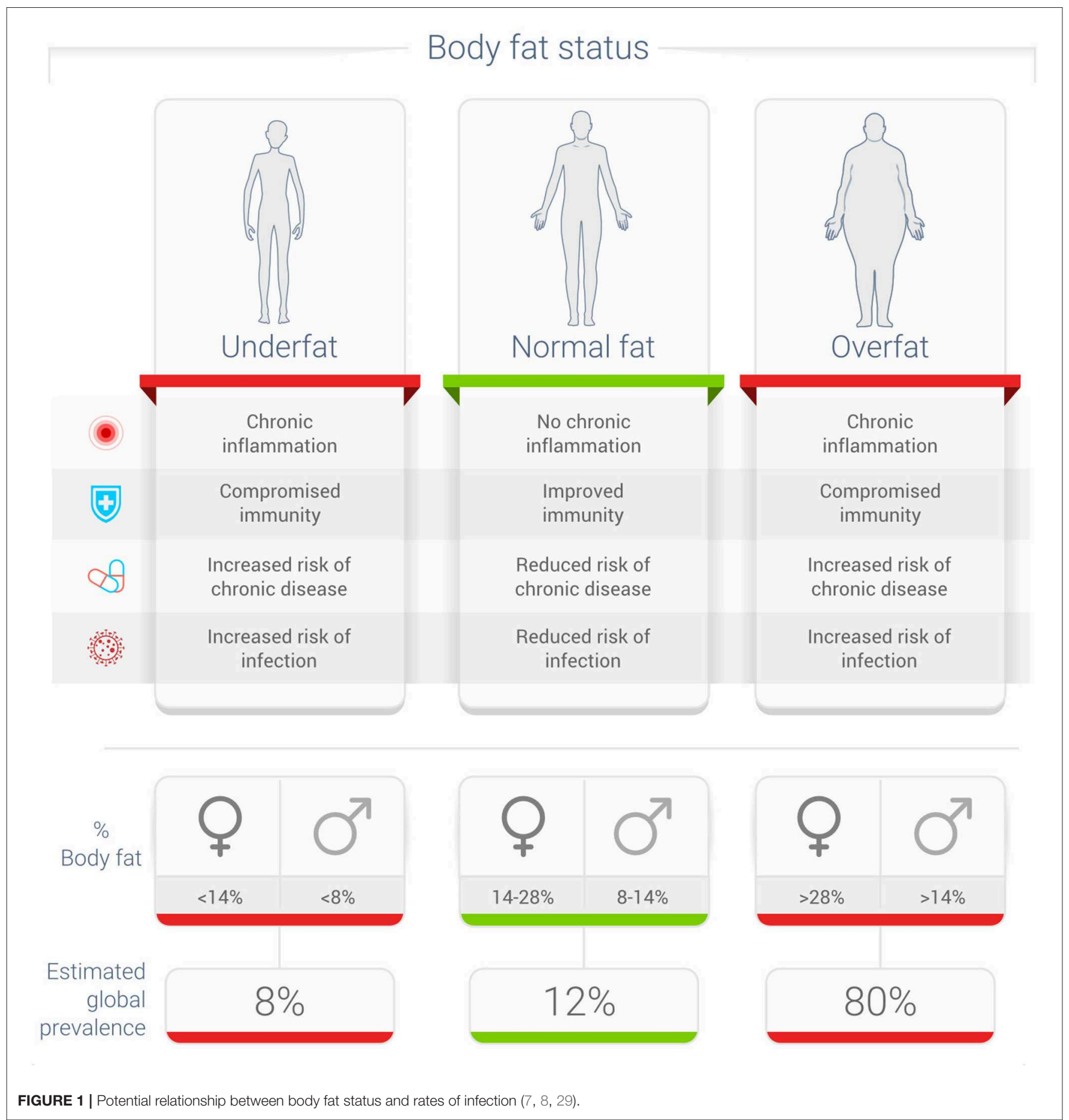

permeability during infection (12). The increased incidence of complications in hospitalized obese patients with influenza infections may be due to increased viral spread to other respiratory areas, further reducing lung function and increasing mortality (44). Overfat is also associated with impaired or reduced fat oxidation rates, which is a hallmark of aging and disease (45).

\section{OTHER LIFESTYLE FACTORS}

Food consumption is a major factor influencing body fat content, the immune system, overall health and the risk of developing diseases (32). The intake of dietary sugar and other refined carbohydrates plays a primary role in the overfat pandemic (29). Importantly, very-low carbohydrate/ketogenic diets have 


\title{
Covid-19: Death through virally-driven hyperinflammation.
}

\author{
Adipose tissue is populated by a number of immune cells \\ including $T$ cells and macrophages.
}

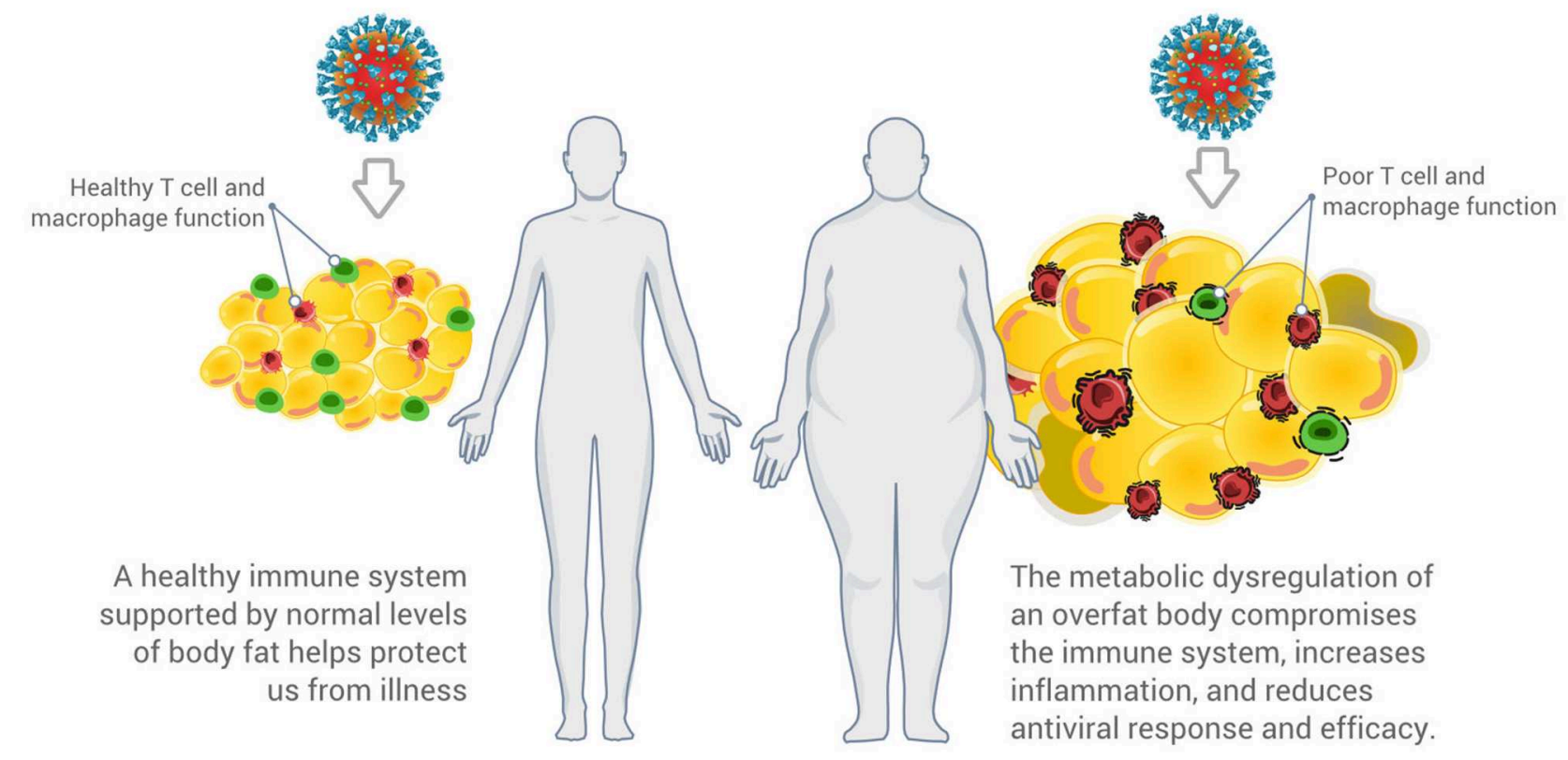

Adipocyte

Necrotic adipocyte

T cell

Macrophage

Covid-19 virus

FIGURE 2 | Illustration of the potential increased risk of death through virally driven hyperinflammation in overfat hosts. Excess adipose tissue promotes systemic inflammation and is characterized by infiltration and activation of immune cells secreting pro-inflammatory mediators, such as cytokines, adipokines, and chemokines, which secrete additional pro-inflammatory molecules. In addition to T cells and macrophages, these immune cells also include neutrophils, B1 and B2 cells, NK cells, and innate lymphoid cells (11).

been successfully applied in conditions that include epilepsy, metabolic disorders, cancer, neuronal loss, and muscle and nerve degeneration $(46,47)$. The diets have also been successful in reducing excess body fat (48) and chronic inflammation (49). Very-low carbohydrate/ketogenic diets may also be protective in promoting a positive immune response against influenza virus infection (50).

While infection rates are still evident in warm weather environments, optimal immune function is also dependent upon a variety of nutritional factors, in addition to regular sunlight exposure to increase vitamin D levels (51). Vitamin D can act as an immune modulator, prevent excessive expression of inflammatory cytokines, increase the "oxidative burst" potential of macrophages, stimulate the expression of anti-microbial peptides in neutrophils, monocytes, natural killer cells, and in epithelial cells lining the respiratory tract where they play a protective role (52). However, those who are overfat have consistently lower vitamin D levels across age, ethnicity, and geography (53). The seasonality of infectious disease outbreaks suggests that environmental conditions have a significant effect on disease risk. In particular, ultraviolet radiation from sun exposure and associated increases in vitamin D levels share common pathways of innate immune activation (54).

\section{CONCLUSION}

While we await more data on Covid-19, comorbidity risk factors that are associated with overfat appear related (1, 5, $6,27)$. The Covid-19 and overfat pandemics are two serious 
public health concerns that are correlated, despite having very different horizons and timescales. Both require urgent attention. Jones (55) writes in the New England Journal of Medicine that, while some experts warn half the world's population could be infected by the end of 2020, resulting in more than 100 million deaths, such a perfect storm is exceedingly rare. It is however, regrettably, one that is possible. Perhaps a more important lesson for the world may be that we control much of our health, and that the prevention of infections

\section{REFERENCES}

1. Zhou F, Yu T, Du R, Fan G, Liu Y, Liu Z, et al. Clinical course and risk factors for mortality of adult inpatients with COVID-19 in Wuhan, China: a retrospective cohort study. Lancet. (2020) 395:105462. doi: 10.1016/S0140-6736(20)30566-3

2. Li Q, Guan X, Wu P, Wang X, Zhou L, Tong Y, et al. Early transmission dynamics in Wuhan, China, of novel coronavirus-infected pneumonia. N Engl J Med. (2020) 382:1199-1207. doi: 10.1056/NEJMoa2001316

3. Hui DS, Azhar EI, Madani TA, Ntoumi F, Kock R, Dar O, et al. The continuing 2019-nCoV epidemic threat of novel coronaviruses to global health - the latest 2019 novel coronavirus outbreak in Wuhan, China. Int $J$ Infect Dis. (2020) 91:264-6. doi: 10.1016/j.ijid.2020. 01.009

4. Guo Z, Xu S, Tong L, Dai B, Liu Y, Xiao D. An artificially simulated outbreak of a respiratory infectious disease. BMC Public Health. (2020) 20:135. doi: 10.1186/s12889-020-8243-6

5. Yang J, Zheng Y, Gou X, Pu K, Chen Z, Guo Q, et al. Prevalence of comorbidities in the novel Wuhan coronavirus (COVID-19) infection: a systematic review and meta-analysis. Int $J$ Infect Dis. (2020). doi: 10.1016/j.ijid.2020.03.017

6. Guan WJ, Ni ZY, Hu Y, Liang WH, Ou CQ, He JX, et al. Clinical characteristics of coronavirus disease 2019 in China. N Engl J Med. (2020). doi: 10.1101/2020.02.06.20020974

7. Maffetone PB, Laursen PB. Revisiting the global overfat pandemic. Front Public Health. (2020) 8:51. doi: 10.3389/fpubh.2020.00051

8. Maffetone PB, Rivera-Dominguez I, Laursen PB. Overfat and underfat: new terms and definitions long overdue. Front Public Health. (2016) 4:279. doi: 10.3389/fpubh.2016.00279

9. Moser JS, Galindo-Fraga A, Ortiz-Hernandez AA, Gu W, Hunsberger S, Galan-Herrera JF, et al. Underweight, overweight, and obesity as independent risk factors for hospitalization in adults and children from influenza and other respiratory viruses. Influenza Other Respir Viruses. (2019) 13:39. doi: 10.1111 /irv. 12618

10. Van Kerkhove MD, Vandemaele KA, Shinde V, Jaramillo-Gutierrez G, Koukounari A, Donnelly CA, et al. Risk factors for severe outcomes following 2009 influenza A (H1N1) infection: a global pooled analysis. PLoS Med. (2011) 8:e100. doi: 10.1371/journal.pmed.1001053

11. Frasca D, McElhaney J. Influence of obesity on pneumococcus infection risk in the elderly. Front Endocrinol. (2019) 10:71. doi: 10.3389/fendo.2019. 00071

12. Honce R, Schultz-Cherry S. Impact of obesity on influenza A virus pathogenesis, immune response, and evolution. Front Immunol. (2019) 10:1071. doi: 10.3389/fimmu.2019.01071

13. Paulsen J, Askim A, Mohus RM, Mehl A, Dewan A, Solligard E, et al. Associations of obesity and lifestyle with the risk and mortality of bloodstream infection in a general population: a 15-year follow-up of 64027 individuals in the HUNT Study. Int J Epidemiol. (2017) 46:1573-81. doi: 10.1093/ije/ dyx091

14. Baik I, Curhan GC, Rimm EB, Bendich A, Willett WC, Fawzi WW. A prospective study of age and lifestyle factors in relation to communityacquired pneumonia in US men and women. Arch Intern Med. (2000) 160:3082-8. doi: 10.1001/archinte.160.20.3082 through a healthy immune system is, not unlike chronic disease and physical impairment, strongly associated with a healthy lifestyle.

\section{AUTHOR CONTRIBUTIONS}

PL and PM conceived the idea for the manuscript through discussion and observation of the COVID-19 pandemic. The manuscript was lead by PM with contributions made by PL.
15. Beck DL. Coronavirus disease 2019 (COVID-19) provides potent reminder of the risk of infectious agents. Cardiology Magazine (2020, March 6).

16. Sumbria D, Berber E, Rouse BT. Factors affecting the tissue damaging consequences of viral infections. Front Microbiol. (2019) 10:2314. doi: $10.3389 /$ fmicb.2019.02314

17. Rothan HA, Byrareddy SN. The epidemiology and pathogenesis of coronavirus disease (COVID-19) outbreak. J Autoimmun. 2020:102433. doi: 10.1016/j.jaut.2020.102433

18. Baig AM, Khaleeq A, Ali U, Syeda H. Evidence of the COVID-19 virus targeting the CNS: tissue distribution, host-virus interaction, and proposed neurotropic mechanisms. ACS Chem Neurosci. (2020) 11:9958. doi: 10.1021 /acschemneuro.0c00122

19. Wang W, Tang J, Wei F. Updated understanding of the outbreak of 2019 novel coronavirus (2019-nCoV) in Wuhan, China. J Med Virol. (2020) 92:4417. doi: $10.1002 / j m v .25689$

20. Jain S, Kamimoto L, Bramley AM, Schmitz AM, Benoit SR, Louie J, et al. Hospitalized patients with 2009 H1N1 influenza in the United States, AprilJune, 2009. N Engl J Med. (2009) 361:1935-44. doi: 10.1056/NEJMoa0 906695

21. Wu L, Zeng T, Deligios M, Milanesi L, Langille MGI, Zinellu A, et al. Age-related variation of bacterial and fungal communities in different body habitats across the young, elderly, and centenarians in Sardinia. mSphere. (2020) 5:e00558-19. doi: 10.1128/mSphere.00558-19

22. Baden LR, Rubin EJ. Covid-19 - the search for effective therapy. N Engl J Med. (2020). doi: 10.1056/NEJMe2005477

23. WHO. Coronavirus Disease 2019 (COVID-19) Situation Report-71. Sydney.

24. Chow N, Fleming-Dutra K, Gierke R, Hall A, Hughes M, Pilishvili T. Preliminary estimates of the prevalence of selected underlying health conditions among patients with coronavirus disease 2019 - United States, February 12-March 28, 2020. MMWR Morb Mortal Wkly Rep. (2020). 69:382-6. doi: 10.15585/mmwr.mm6913e2

25. Maffetone PB, Rivera-Dominguez I, Laursen PB. Overfat adults and children in developed countries: the public health importance of identifying excess body fat. Front Public Health. (2017) 5:190. doi: 10.3389/fpubh.2017. 00190

26. Bialek S, Boundy E, Bowen V, Chow N, Cohn A, Dowling N. Severe outcomes among patients with coronavirus disease 2019 (COVID-19) - United States, February 12-March 16, 2020. MMWR Morb Mortal Wkly Rep. (2020) 69:3436. doi: 10.15585/mmwr.mm6912e2

27. Verity R, Okell LC, Dorigatti I, Winskill P, Whittaker C, Imai N, et al. Estimates of the severity of coronavirus disease 2019: a model-based analysis. Lancet Infect Dis. (2020). doi: 10.1016/S1473-3099(20)30243-7

28. Osborn O, Olefsky JM. The cellular and signaling networks linking the immune system and metabolism in disease. Nat Med. (2012) 18:36374. doi: $10.1038 / \mathrm{nm} .2627$

29. Maffetone PB, Laursen PB. The prevalence of overfat adults and children in the US. Front Public Health. (2017) 5:290. doi: 10.3389/fpubh.2017. 00290

30. Salvator H, Grassin-Delyle S, Naline E, Brollo M, Fournier C, Couderc $\mathrm{LJ}$, et al. Contrasting effects of adipokines on the cytokine production by primary human bronchial epithelial cells: inhibitory effects of adiponectin. Front Pharmacol. (2020) 11:56. doi: 10.3389/fphar.2020. 00056 
31. Zhou Y, Cowling BJ, Wu P, Chan WM, Lee SY, Lau EH, et al. Adiposity and influenza-associated respiratory mortality: a cohort study. Clin Infect Dis. (2015) 60:e49-57. doi: 10.1093/cid/civ060

32. Polito R, Nigro E, Messina A, Monaco ML, Monda V, Scudiero $\mathrm{O}$, et al. Adiponectin and Orexin-A as a potential immunity link between adipose tissue and central nervous system. Front Physiol. (2018) 9:982. doi: 10.3389/fphys.2018.00982

33. Coelho M, Oliveira T, Fernandes R. Biochemistry of adipose tissue: an endocrine organ. Arch Med Sci. (2013) 9:191200. doi: 10.5114/aoms.2013.33181

34. Magnussen CG, Smith KJ. Pediatric blood pressure and adult preclinical markers of cardiovascular disease. Clin Med Insights Blood Disord. (2016) 9:1-8. doi: 10.4137/CMBD.S18887

35. Scappaticcio L, Maiorino MI, Bellastella G, Giugliano D, Esposito K. Insights into the relationships between diabetes, prediabetes, and cancer. Endocrine. (2017) 56:231-9. doi: 10.1007/s12020-016-1216-y

36. Lauby-Secretan B, Scoccianti C, Loomis D, Grosse Y, Bianchini F, Straif K, et al. Body fatness and cancer-viewpoint of the IARC Working Group. N Engl J Med. (2016) 375:794-8. doi: 10.1056/NEJMsr1606602

37. Virgin HW, Wherry EJ, Ahmed R. Redefining chronic viral infection. Cell. (2009) 138:30-50. doi: 10.1016/j.cell.2009.06.036

38. Poulain M, Doucet M, Major GC, Drapeau V, Series F, Boulet LP, et al. The effect of obesity on chronic respiratory diseases: pathophysiology and therapeutic strategies. CMAJ. (2006) 174:1293-9. doi: 10.1503/cmaj. 051299

39. Rodriguez A, Socias L, Guerrero JE, Figueira JC, Gonzalez N, MaraviPoma E, et al. Pandemic influenza A in the ICU: experience in Spain and Latin America. GETGAG/SEMICYUC/(Spanish Working Group on Severe Pandemic Influenza A/SEMICYUC). Med Intensiva. (2010) 34:87-94. doi: 10.1016/j.medin.2009.12.005

40. Park HL, Shim SH, Lee EY, Cho W, Park S, Jeon HJ, et al. Obesity-induced chronic inflammation is associated with the reduced efficacy of influenza vaccine. Hum Vaccin Immunother. (2014) 10:1181-6. doi: 10.4161/hv. 28332

41. Rebeles J, Green WD, Alwarawrah Y, Nichols AG, Eisner W, Danzaki K, et al. Obesity-induced changes in T-cell metabolism are associated with impaired memory T-cell response to influenza and are not reversed with weight loss. $J$ Infect Dis. (2019) 219:1652-61. doi: 10.1093/infdis/jiy700

42. Kim YH, Kim JK, Kim DJ, Nam JH, Shim SM, Choi YK, et al. Diet-induced obesity dramatically reduces the efficacy of a 2009 pandemic H1N1 vaccine in a mouse model. J Infect Dis. (2012) 205:244-51. doi: 10.1093/infdis/ jir731

43. Taubenberger JK, Morens DM. The pathology of influenza virus infections. Annu Rev Pathol. (2008) 3:499-522. doi: 10.1146/annurev. pathmechdis.3.121806.154316
44. Riquelme R, Jimenez P, Videla AJ, Lopez H, Chalmers J, Singanayagam A, et al. Predicting mortality in hospitalized patients with $2009 \mathrm{H} 1 \mathrm{~N} 1$ influenza pneumonia. Int J Tuberc Lung Dis. (2011) 15:542-6. doi: 10.5588/ijtld.10.0539

45. Anderson RM, Weindruch R. Metabolic reprogramming in dietary restriction. Interdiscip Top Gerontol. (2007) 35:18-38. doi: 10.1159/000096554

46. Li RJ, Liu Y, Liu HQ, Li J. Ketogenic diets and protective mechanisms in epilepsy, metabolic disorders, cancer, neuronal loss, and muscle and nerve degeneration. J Food Biochem. (2020) 44:e13140. doi: 10.1111/jfbc.13140

47. Li J, Liu Y, Liu HQ, Chen L, Li RJ. Ketogenic diet potentiates electrical stimulation-induced peripheral nerve regeneration after sciatic nerve crush injury in rats. Mol Nutr Food Res. (2020) 64:e1900535. doi: 10.1002/mnfr.201900535

48. Brinkworth GD, Noakes M, Clifton PM, Buckley JD. Effects of a low carbohydrate weight loss diet on exercise capacity and tolerance in obese subjects. Obesity. (2009) 17:1916-23. doi: 10.1038/oby.2009.134

49. Gleeson MW, Dickson RC. Quelling inflammation with ketosis and steric chemistry. Clin Transl Gastroenterol. (2016) 7:e145. doi: 10.1038/ctg.2016.6

50. Goldberg EL, Molony RD, Kudo E, Sidorov S, Kong Y, Dixit $\mathrm{VD}$, et al. Ketogenic diet activates protective gammadelta $\mathrm{T}$ cell responses against influenza virus infection. Sci Immunol. (2019) 4:eaav2026. doi: 10.1126/sciimmunol.aav2026

51. Elmadfa I, Meyer AL. The role of the status of selected micronutrients in shaping the immune function. Endocr Metab Immune Disord Drug Targets. (2019) 19:1100-15. doi: 10.2174/1871530319666190529101816

52. Cannell JJ, Vieth R, Umhau JC, Holick MF, Grant WB, Madronich S, et al. Epidemic influenza and vitamin D. Epidemiol Infect. (2006) 134:112940. doi: 10.1017/S0950268806007175

53. Walsh JS, Bowles S, Evans AL. Vitamin D in obesity. Curr Opin Endocrinol Diabetes Obes. (2017) 24:389-94. doi: 10.1097/MED.0000000000000371

54. Abhimanyu, Coussens AK. The role of UV radiation and vitamin D in the seasonality and outcomes of infectious disease. Photochem Photobiol Sci. (2017) 16:314-38. doi: 10.1039/C6PP00355A

55. Jones DS. History in a crisis - lessons for Covid-19. N Engl J Med. (2020). doi: 10.1056/NEJMp2004361

Conflict of Interest: PM is part owner of a business that promotes health and wellness (MAFF PTY). PL is part owner of a business that promotes health and wellness (HIIT Science Inc).

Copyright (C) 2020 Maffetone and Laursen. This is an open-access article distributed under the terms of the Creative Commons Attribution License (CC BY). The use, distribution or reproduction in other forums is permitted, provided the original author(s) and the copyright owner(s) are credited and that the original publication in this journal is cited, in accordance with accepted academic practice. No use, distribution or reproduction is permitted which does not comply with these terms. 